\title{
Modelling tidally induced larval dispersal over Anton Dohrn Seamount
}

\author{
Nataliya Stashchuk ${ }^{1}$ (D) . Vasiliy Vlasenko ${ }^{1} \cdot$ Kerry L. Howell ${ }^{1}$ \\ Received: 26 September 2017 / Accepted: 17 July 2018 / Published online: 9 August 2018 \\ (C) The Author(s) 2018
}

\begin{abstract}
Massachusetts Institute of Technology general circulation model is used for the analysis of larval dispersal over Anton Dohrn Seamount (ADS), North Atlantic. The model output validated against the in situ data collected during the 136th cruise of the RRS 'James Cook' in May-June 2016 allowed reconstruction of the details of the baroclinic tidal dynamics over ADS. The obtained velocities were used as input data for a Lagrangian-type passive particle tracking model to reproduce the larval dispersal of generic deep-sea water invertebrate species. It was found that the residual tidal flow over ADS has a form of a pair of dipoles and cyclonic and anti-cyclonic eddies located at the seamount periphery. In the vertical direction, tides form upward motions above the seamount summit. These currents control local larval dispersal and their escape from ADS. The model experiment with a large number of particles (7500) evenly seeded on the ADS surface has shown that the trajectory of every individual particle is sensitive to the initial position and the tidal phase where and when it is released. The vast majority of the particles released above $1000 \mathrm{~m}$ depth remain seated in the same depth band where they were initially released. Only $8 \%$ of passive larvae were able to remain in suspension until competent to settle (maximise dispersal capability) and settle (make contact with the bottom) within the specified limits for this model. It was found that every tenth larval particle could leave the seamount and had a chance to be advected to any other remotely located seamount.
\end{abstract}

Keywords Larva dispersion · Tidal residual currents · Baroclinic tides

\section{Introduction}

Cold-water corals are typical habitats for all oceanic banks and seamounts. The reef-forming species attract the interest of marine biologists over last decades. Globally, they occur within a wide depth range (40-3500 m) in well-defined depth zones parallel to the shelf break, or the rim of offshore banks and seamounts (Buhl-Mortensen et al. 2015). The

This article is part of the Topical Collection on the 9th International Workshop on Modeling the Ocean (IWMO), Seoul, Korea, 3-6 July 2017

Responsible Editor: Jarle Berntsen

Nataliya Stashchuk

nstashchuk@plymouth.ac.uk

Vasiliy Vlasenko

vvlasenko@plymouth.ac.uk

Kerry L. Howell

kerry.howell@plymouth.ac.uk

1 University of Plymouth, Drake Circus, Plymouth, PL4 8AA, UK highest population density of one of them, the Lophelia pertusa, known so far has been found along the Norwegian coast and in the eastern North Atlantic (Buhl-Mortensen et al. 2017).

In the marine environment, the adult corals are immobile; although at a larval stage, they live in the water column for a certain period of time, moving with currents before settling down in a new area. It is larval dispersal that keeps distant populations connected.

Investigation of benthic communities living at seamounts in the Northern Atlantic was conducted during the 136th cruise of the RRS 'James Cook' (hereafter, JC136) in May-June 2016. The study covered a wide area using the remotely operated vehicle (ROV) ISIS 4500 which collected animal samples in the area of the Rockall Trough, from the Wyville Thomson Ridge, Rosemary, George Bligh, Rockall and Anton Dohrn Seamounts. The marine biological surveying was accompanied by oceanographic measurements that included deployment of two moorings at the periphery of Anton Dohrn Seamount (ADS) and a series of CTD stations (Fig. 1a). The smoothed temperature and salinity profiles recorded at station 1 (20 km from seamount) are presented in Fig. 1b. 

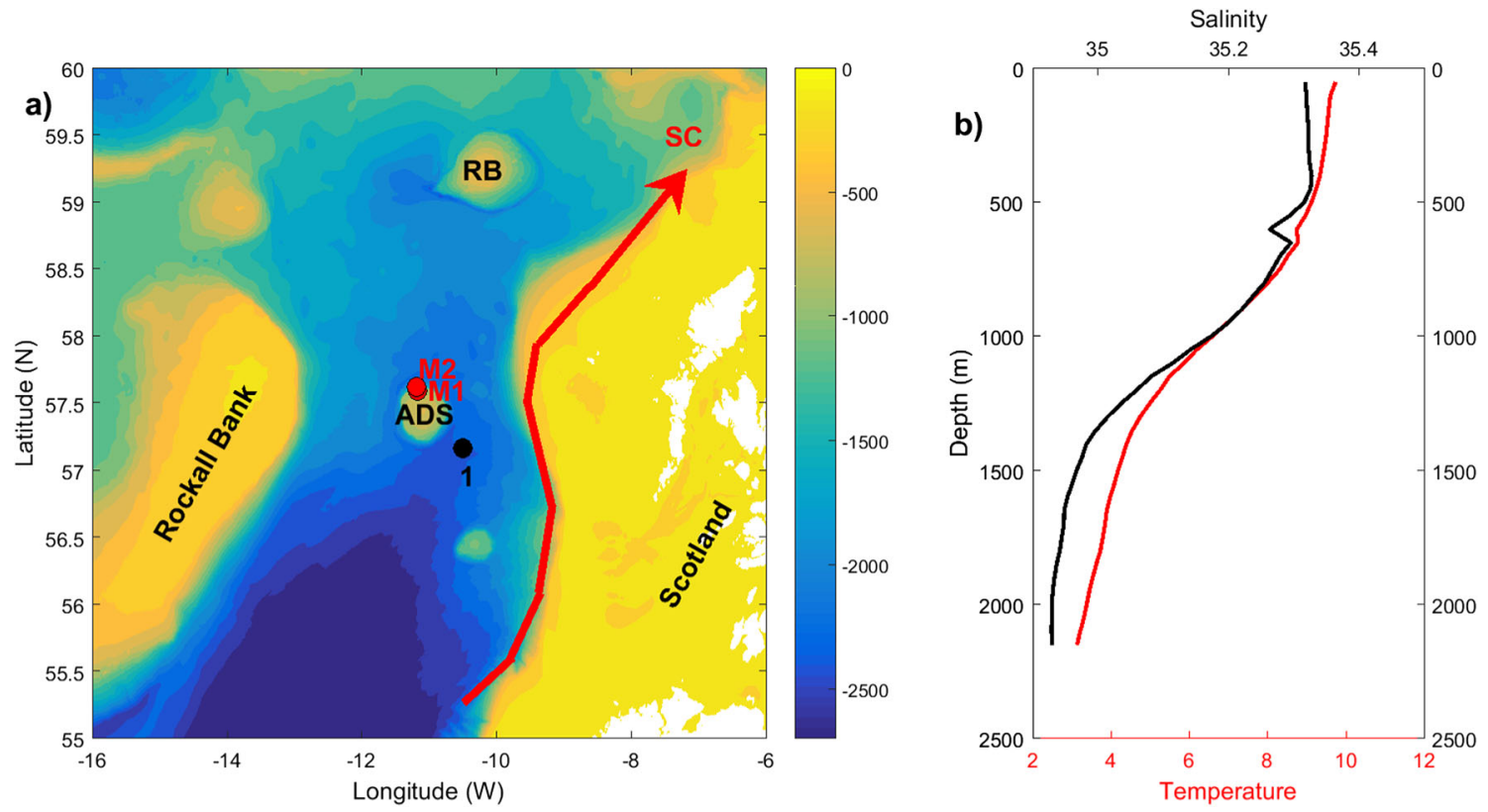

Fig. 1 a Map of Rockall Trough showing Anton Dohrn Seamount (ADS) and positions of moorings M1 and M2. RB, Rosemary Bank. The red line shows the route of the Slope Current (SC). b Temperature and salinity profile measured at CTD station 1

Anton Dohrn Seamount is a guyot with its summit at nearly $600 \mathrm{~m}$ depth situated in the central part of the Rockall Trough. It is topographically complex and harbours diverse biological assemblages, including communities dominated by cold water corals and sponges (Davies et al. 2015).

The strongest current in the Rockall Trough area is the Slope Current (SC) schematically shown in Fig. 1a. It resembles a jet stream transporting Atlantic waters along the edge of the continental slope northward with maximum velocities $0.15-0.3 \mathrm{~m} \mathrm{~s}^{-1}$ (Sherwin et al. 2015). Its core is confined to the slope above the 400-500-m isobath.

Note that the reported SC is situated at a considerable distance from ADS (see Fig. 1a) and hardly contributes to the dynamics around ADS. All other currents in the area are either much weaker or located in the surface layer. In fact, the summit of ADS is below $600 \mathrm{~m}$ deep, so it is not expected that any surface current like wind-driven flows (their penetration depth is less than $300 \mathrm{~m}$ ) can influence the water circulation around ADS. The only dynamical process that can significantly affect the whole water column is the tide. Tidal currents interacting with rough bottom topography generate internal waves.

Henry et al. (2014) conducted investigations of the influence of internal tidal waves on the megabenthic communities (below $1000 \mathrm{~m}$ water depth) in the area of the Hebrides Terrace Seamount. They found that the internal tides may significantly enhance the biological diversity on considered and adjacent seamounts in the Rockall Trough. The authors also assumed that coral populations at bathyal depths have higher tendency to become isolated over a given distance due to the currents decreasing with depth (i.e. the larvae might not be able to travel far away from the place of its origin). Note, however, that this conclusion is not valid for the areas with a substantial internal tidal activity which produces strong currents in the deep, as well.

The principal aim of the present study is to investigate the influence of internal tidal currents generated over Anton Dohrn Seamount on the coral larval dispersal based on the model output (discussed below) and the data collected in situ in the ADS area during the JC136 cruise in MayJune, 2016. To record tidal currents, moorings M1 and M2 were deployed in the area during the cruise (see Fig. 1a). Each mooring was equipped with up-looking 75$\mathrm{kHz}$ Acoustic Doppler Current Profiler (ADCP) installed $50 \mathrm{~m}$ above the bottom, and $600 \mathrm{KHz}$ down-looking ADCP placed just below it for measuring the flow regime of the bottom boundary layer. Figure 2 presents the currents' time series recorded at moorings M1 and M2. They show the predominance of tidal motions over any other process in the whole water column.

The observational data were used for further validation of numerical reconstruction of the internal tidal currents in the ADS area (Vlasenko et al. 2018). The model-predicted velocities were the background fields for a Lagrangetype model that predicts the process of larval dispersal considering larvae as floating passive particles that move with internal tidal currents.

A similar study was conducted by Bartsch and Coombs (1997) who made predictions for blue whiting larval transport by the Shelf-Edge Current along the European 

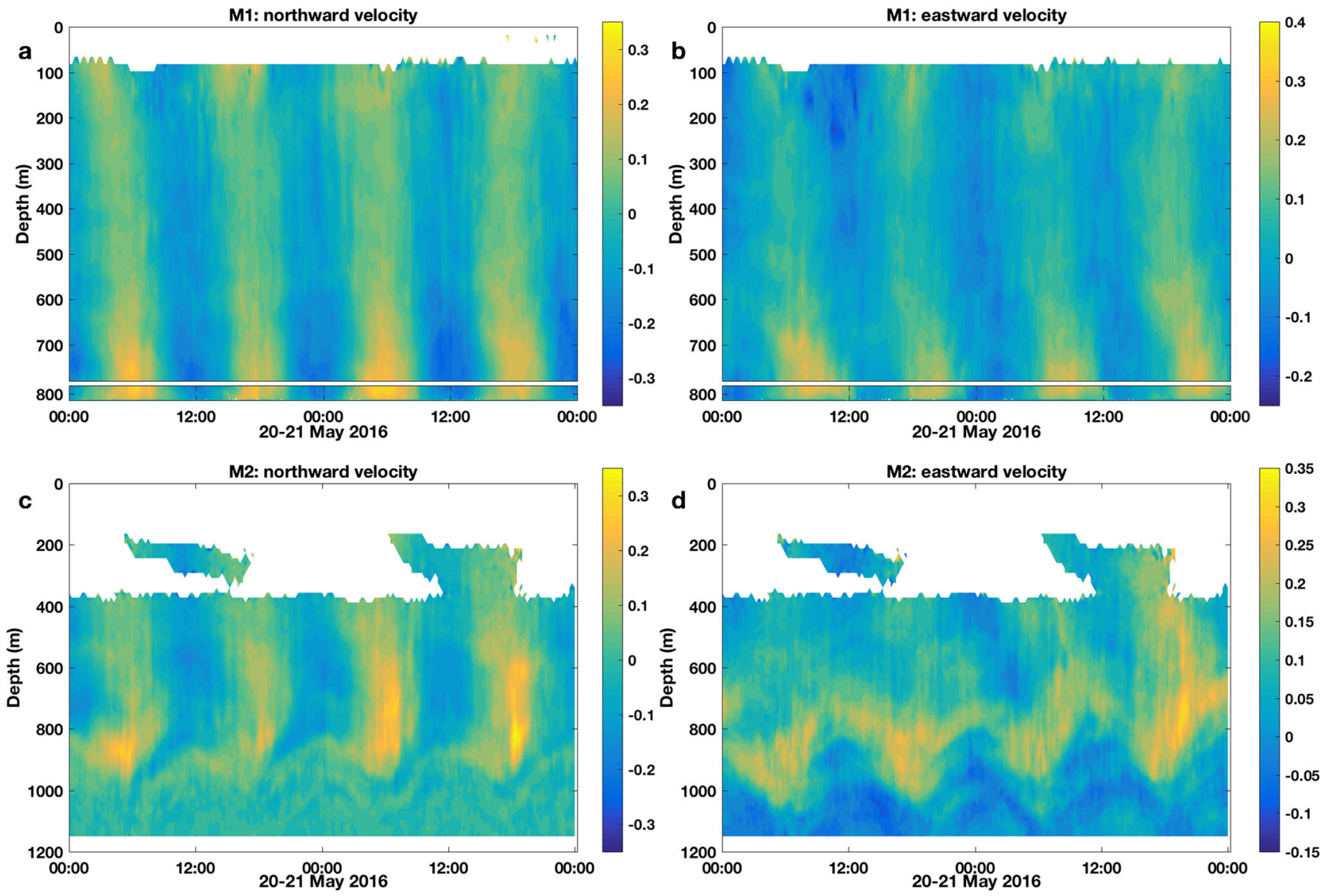

Fig. 2 Mooring 1: a northward and $\mathbf{b}$ eastward in situ velocity time series. Mooring 2: c northward and $\mathbf{d}$ eastward in situ velocity time series

coast. Thiem et al. (2006) reported another modelling effort with the focus on the influence of an along slope jet current on the position of Lophelia pertusa coral reefs outside the Norwegian coast. Their model results suggest that the majority of the Lophelia pertusa reefs are concentrated in the areas along the shelf edges where slope currents provide a good supply of food.

In the present paper, we use a similar approach for investigation of the larvae transport over ADS. The paper is organised as follows. Section 2 presents the details of the setting of the hydrodynamic model and description of the Lagrangian model. Section 3 discusses an experiment on larvae dispersal. Finally, conclusions are summarised in Section 4.

\section{Models}

\subsection{Hydrodynamical model}

The Massachusetts Institute of Technology general circulation model (Marshall et al. 1997) was used for simulations of internal tides in the ADS area. The model was forced by the principal tidal harmonic $\mathrm{M}_{2}$ added to the right-hand side of the momentum balance equations as a tidal potential. Stashchuk et al. (2014) presents the details of the procedure of tidal implementation into the MITgcm.

The parameters for the tidal forcing were taken from the inverse tidal model TPXO8.1 (Egbert and Erofeeva 2002); specifically, the maximum tidal discharges for eastward and northward direction were 96.3 and $50 \mathrm{~m}^{2} \mathrm{~s}^{-1}$, respectively, and the phase shift between the two equals $\pi / 4.1$.

The model domain included a $768 \times 794$ mesh grid in which only a central part of $512 \times 538$ grid points with the horizontal resolution of $\Delta x=\Delta y=115 \mathrm{~m}$ was used for the analysis. The rest of the model domain was an "ad hoc" addition, i.e. the lateral boundary layers, with a two-step telescopically increased grid: (i) 118 grid points with the increasing periphery-ward grid step from 115 to $5500 \mathrm{~m}$ and (ii) last ten grid points where the grid step was increased up to $2 \cdot 10^{8} \mathrm{~m}$. The addition of such an ad hoc area to the domain with seamount allows providing propagation of generated internal and barotropic waves to the boundaries during a long time without reflection from them.

The coefficients of horizontal viscosity in the model were taken at the level of $10^{-2} \mathrm{~m}^{2} \mathrm{~s}^{-1}$. The vertical turbulent 
closure for the coefficients of vertical viscosity $v$ and diffusivity $\kappa$ was provided by the Richardson number dependent parametrisation, Pacanowski and Philander (1981):

$$
\begin{aligned}
& v=\frac{v_{0}}{(1+\alpha \mathrm{Ri})^{n}}+v_{b}, \\
& \kappa=\frac{v}{(1+\alpha \mathrm{Ri})}+\kappa_{b} .
\end{aligned}
$$

Here, $\mathrm{Ri}$ is the Richardson number, $\mathrm{Ri}=N^{2}(z) /\left(u_{z}^{2}+v_{z}^{2}\right)$, and $N^{2}(z)=-g / \rho(\partial \rho / \partial z)$ is the buoyancy frequency ( $g$ is the acceleration due to gravity, and $\rho$ is water density), $u$ and $v$ are the components of horizontal velocity; $v_{b}=10^{-5} \mathrm{~m}^{2} \mathrm{~s}^{-1}$ and $\kappa_{b}=10^{-5} \mathrm{~m}^{2} \mathrm{~s}^{-1}$ are the background parameters, $v_{0}=1.5 \cdot 10^{-2} \mathrm{~m}^{2} \mathrm{~s}^{-1}, \alpha=5$ and $n=1$ are the adjustable parameters. Such a parametrisation increases coefficients $v$ and $\kappa$ in the areas where the Richardson number is small which should take into account the mixing processes induced by the shear instabilities and breaking internal waves.

The model velocity time series (sampling interval was 60 s) presented in Fig. 3 were compared against the in
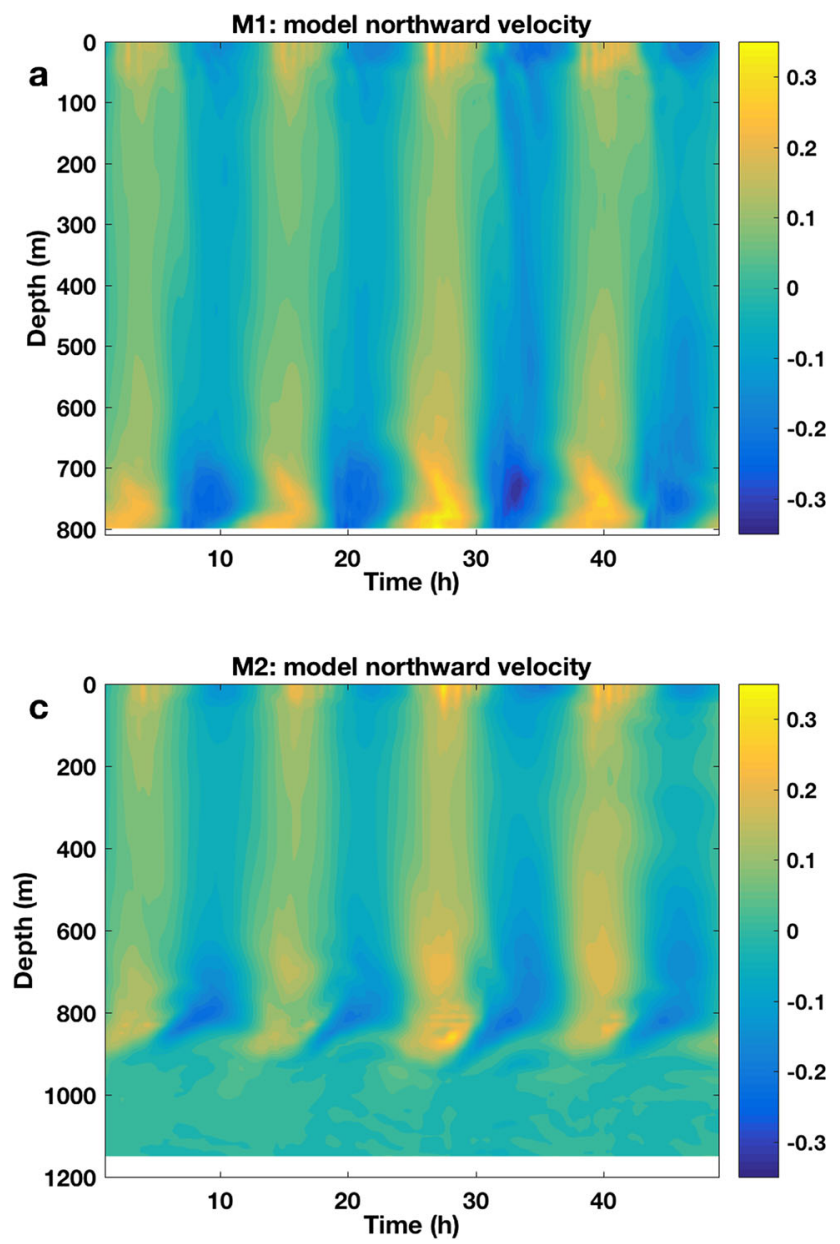

situ data collected in the ADS area during JC136th cruise (Fig. 2). Consistency of both, in situ recorded and model time series, is seen from the comparison of the panels. A more comprehensive comparative analysis that shows the ability of the model in the replication of the near bank dynamics is presented in Vlasenko et al. (2018).

\subsection{Lagrangian model}

One of the methods for investigation of the larvae dispersion could be the addition of an extra passive tracer transport equation into the governing system considering the evolution of the tracer. The MITgcm has such an option, and we applied this method for modelling of the in situ experiment conducted in the Jones Bank area (Celtic Sea) (Stashchuk et al. 2014). It was found there that after 4 days of the in situ and model experiments, the Rhodamine concentration fell down below the threshold of its detection both in observation and in the numerical fields. That is the reason why we chose here a Lagrangian-type model for tracing the larvae. It is shortly outlined below.
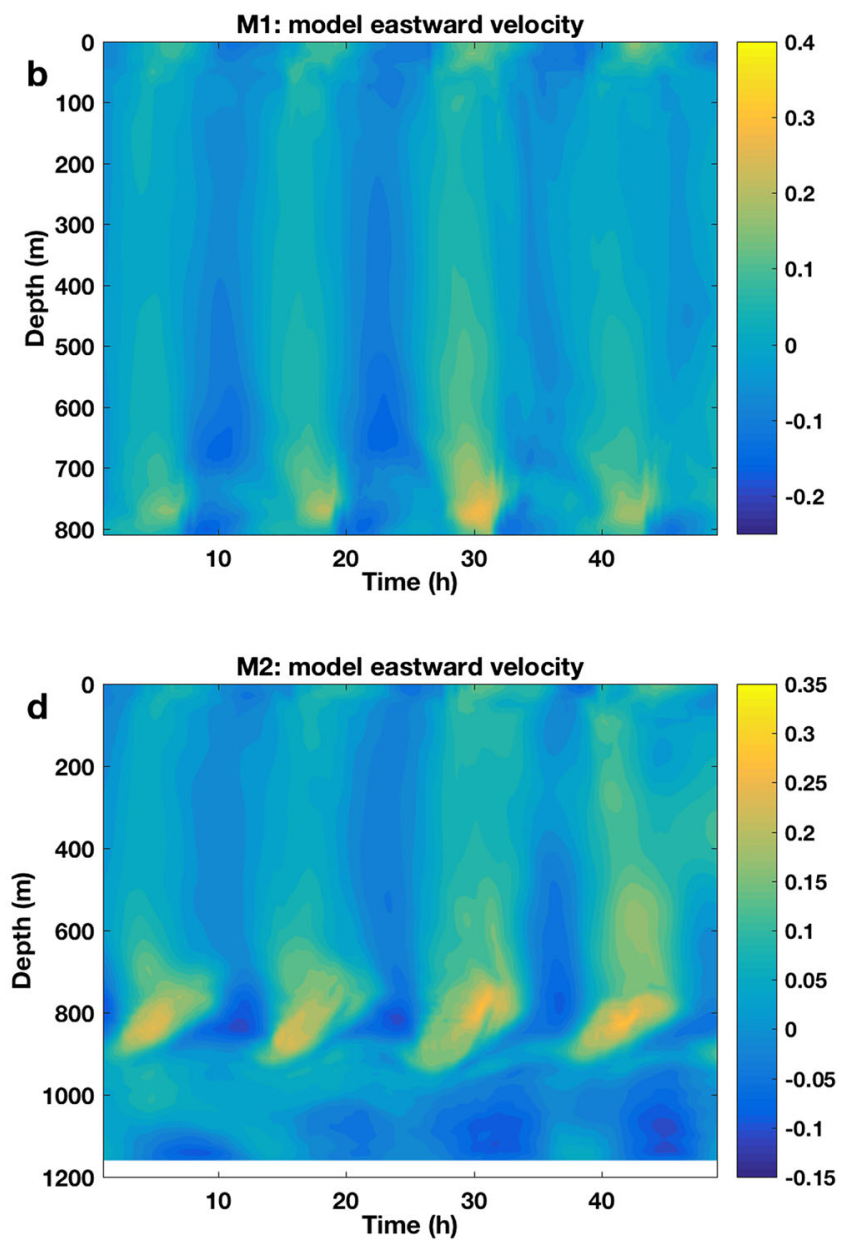

Fig. 3 Mooring 1: a northward and $\mathbf{b}$ eastward model velocity time series. Mooring 2: $\mathbf{c}$ northward and $\mathbf{d}$ eastward model velocity time series 
Three-dimensional matrices of the velocity vectors $\vec{U}(u, v, w)$ (here, $w$ is the vertical velocity component) from the model explained above with a 5-min time interval were used for calculation of trajectories of passive particles over 40 days. The procedure of the trajectory calculations is as follows. Suppose the initial position of a passive particle was at a some grid point $\overrightarrow{x_{0}}\left(x_{0}, y_{0}, z_{0}\right)$. As long as the velocity field vector $\vec{U}\left(u_{0}, v_{0}, w_{0}\right)$ is known from the model output, $\Delta t$ time later the particle moves to the position with coordinates $\vec{x}(x, y, z)$

$$
\vec{x}=\vec{x}_{0}+\vec{U} \cdot \Delta t
$$

which is inside a grid cell of the hydrodynamical model (Fig. 4). A new position of the particle does not necessarily coincide with nodal points of the grid, and thus, its velocity $\vec{U}(u, v, w)$ is unknown and must be calculated to proceed with the trajectory reconstruction. It can be done using a trilinear interpolation method. Several successive steps of this procedure are presented below.

At the first stage, a differences vector $\overrightarrow{x_{d}}\left(x_{d}, y_{d}, z_{d}\right)$ between the coordinates of grid nodes and particle position is defined:

$x_{d}=\frac{x-x_{0}}{x_{1}-x_{0}}, \quad y_{d}=\frac{y-y_{0}}{y_{1}-y_{0}}, \quad z_{d}=\frac{z-z_{0}}{z_{1}-z_{0}}$.

Here, $\overrightarrow{x_{0}}$ and $\overrightarrow{x_{1}}$ are the coordinates of the grid nodes.
The velocities at the corners of the plain that crosses the particle and the grid cell should be found (Fig. 4):

$$
\begin{aligned}
& \vec{U}_{00}=\vec{U}_{000}\left(1-x_{d}\right)+\vec{U}_{100} x_{d}, \\
& \vec{U}_{01}=\vec{U}_{001}\left(1-x_{d}\right)+\vec{U}_{101} x_{d}, \\
& \vec{U}_{10}=\vec{U}_{010}\left(1-x_{d}\right)+\vec{U}_{110} x_{d}, \\
& \vec{U}_{11}=\vec{U}_{011}\left(1-x_{d}\right)+\vec{U}_{111} x_{d} .
\end{aligned}
$$

The next step is the definition of the velocity at the ends of the vertical line that crosses the particle (Fig. 4):

$$
\vec{U}_{0}=\vec{U}_{00}\left(1-y_{d}\right)+\vec{U}_{10} y_{d},
$$

$\vec{U}_{1}=\vec{U}_{01}\left(1-y_{d}\right)+\vec{U}_{11} y_{d}$.

Finally, the velocity at the position of the particle is calculated as follows:

$\vec{U}=\left(\vec{U}_{0}\left(1-z_{d}\right)-\vec{U}_{1}\right) z_{d}$.

Procedures (3)-(6) allow calculation of a new position of the particle and its velocity every 5 min using the model output. The described algorithm is repeated again and again until the whole 40-day particle trajectory is calculated.

Concerning the time of model prediction, Larsson et al. (2014) in their laboratory investigations of embryogenesis and larval development of cold-water coral Lophelia pertusa have shown that nematocysts appear when larvae are 30 days old. After this time, they can settle and give rise to a new coral colony. We have used a planktonic larval duration of 40 days. That is close to 43 days reported by Hilário

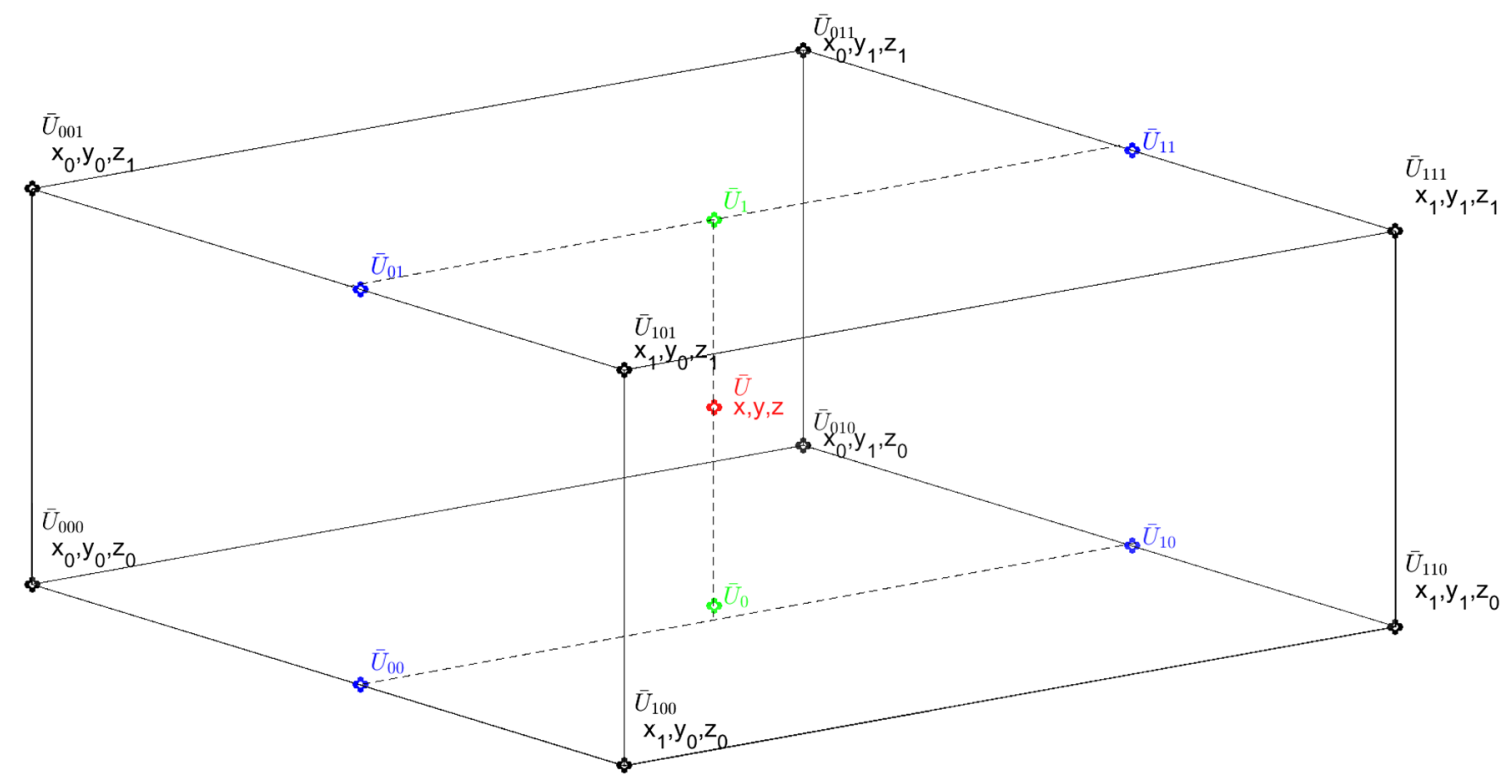

Fig. 4 Scheme of trilinear interpolation 
Fig. 5 a Arrows show the residual currents generated by tides over Anton Dohrn Seamount at the depth of $700 \mathrm{~m}$. The largest arrows scale corresponds to $0.11 \mathrm{~m} \mathrm{~s}^{-1}$. Cross sections of vertical velocities along transects 1-1 (b) and 2-2 (c). The model runs were conducted with $A=50 \mathrm{~m}^{2} \mathrm{~s}^{-1}$, $B=93.6 \mathrm{~m}^{2} \mathrm{~s}^{-1}$, and $\phi=\pi / 4.1$

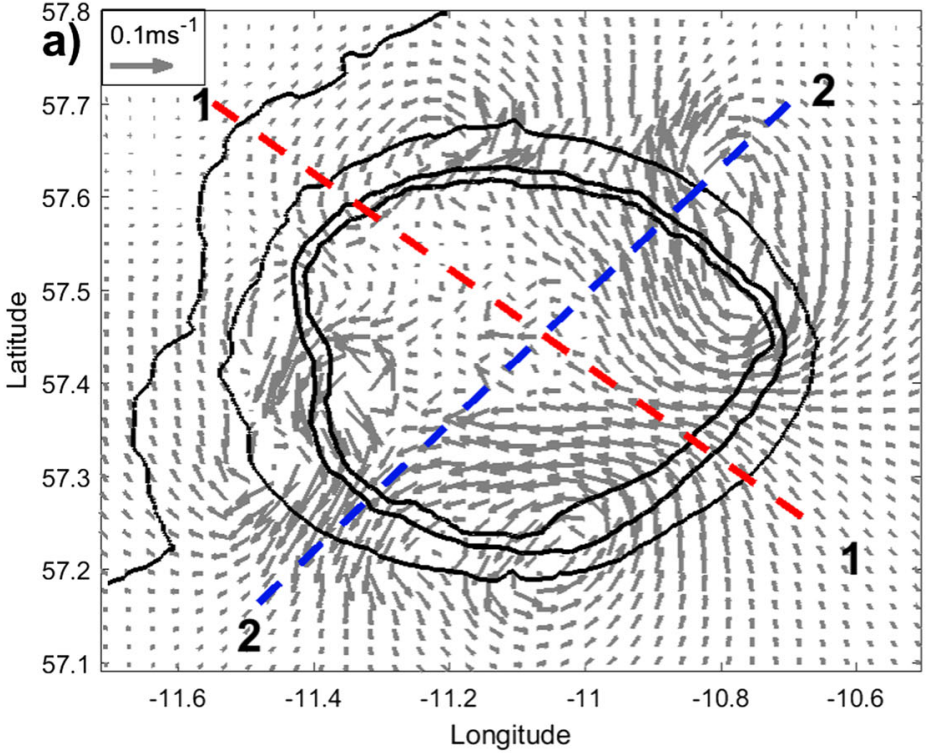

1-1
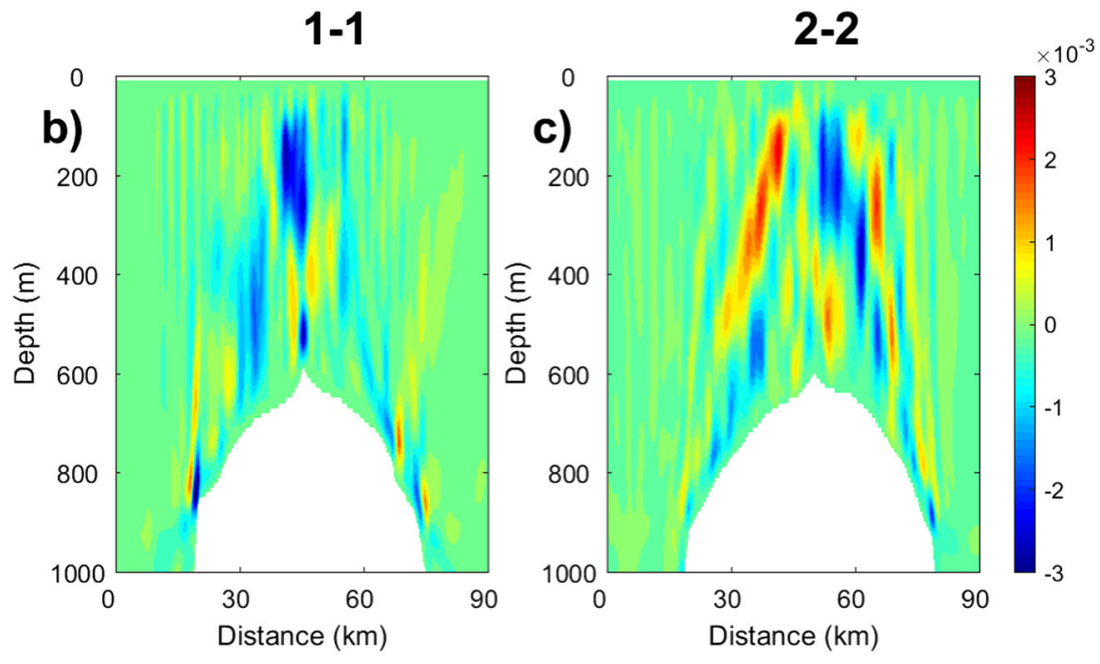

a) particles released at the same position but at different tidal phases $\Delta t$ after the beginning of the tidal cycle: $\mathbf{a} \Delta t=3 \mathrm{~h}$ and $\mathbf{b} \Delta t=9 \mathrm{~h}$
$\Delta \mathrm{t}=\mathbf{3 h}$

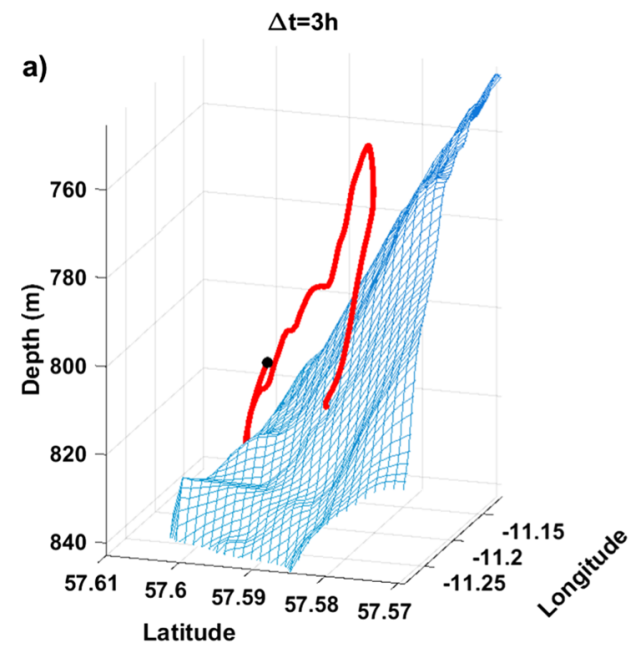


et al. (2015) as the mean minimum duration for eurybathic species. In our methodology, we followed an assumption that the larvae can be considered as particles with a neutral buoyancy that are unable to swim by themselves.

\section{Residual currents}

Theory wise, a weak tidal flow interacting with nearly flat bottom topography generates systems of linear internal waves that do not produce any residual water transport. Trajectories of fluid particles in such waves are circular so that all particles return to their initial positions after one tidal cycle. However, the situation is getting more complicated with a moderate tidal forcing and rough topography. Strong nonlinear advection accompanied by bottom friction introduces an asymmetry in the particle trajectories which ultimately leads to the generation of residual tidal currents.

It is clear that the larva trajectories depend on the spatial structure and intensity of the possible residual currents. Pingree and Maddock (1980) showed that the tidally induced frictional stresses over sloping ideal seamount result in the generation of four eddies located at its periphery.

Figure 5 shows residual currents over ADS calculated for the conditions of the JC136 cruise (tidal parameters and water stratification were taken as those recorded during the cruise; Fig. 1). The residual currents were calculated using 120-h hydrodynamical model velocity outputs applying a procedure of time averaging. The overall structure of the residual currents looks similar to those obtained by Pingree and Maddock (1980) for a Gaussian-type symmetrical seamount. Specifically, one can identify two dominant dipoles of eddies. However, taking into account that ADS is not an ideal seamount but has a more complicated three-dimensional form, the tide produces some extra smallscale eddies. Local small-scale bottom features control the positions and shape of these vortexes.

Figures $5 \mathrm{~b}$ and $5 \mathrm{c}$ show two transects with residual vertical currents. Here, a number of local vertical circulation cells are seen. The fluxes above the summit are directed mostly upward and restricted with the depth of $400 \mathrm{~m}$.

Taking into account a periodical nature of tidal motions, it is expected that neutral particles, being released at different moments of the tidal cycle (flood, ebb, slack), can move in different directions. The difference in particle propagation is seen in Fig. 6. Here, the trajectories of two particles are presented that were initially located at the same position $5 \mathrm{~m}$ above the bottom but were released at different phases of the tidal cycle with a 6-h time lag. Having the difference in particle trajectories in mind, it was decided to consider four different scenarios of particle dispersion, specifically when they were released with 3-h intervals during one tidal cycle.
Fig. 7 The initial positions of particles seeded with $350 \mathrm{~m}$ spatial interval. The particles are shown in different colours depending on water depth: blue colour for the particle located above $600 \mathrm{~m}$ depth, green for 600-700 m depth interval, red for depths 700-800 m, cyan for 800-900 m, yellow for $900-1000$ $\mathrm{m}$, magenta for $1000-1100 \mathrm{~m}$, and the orange colour for 1100-1200 m depth interval

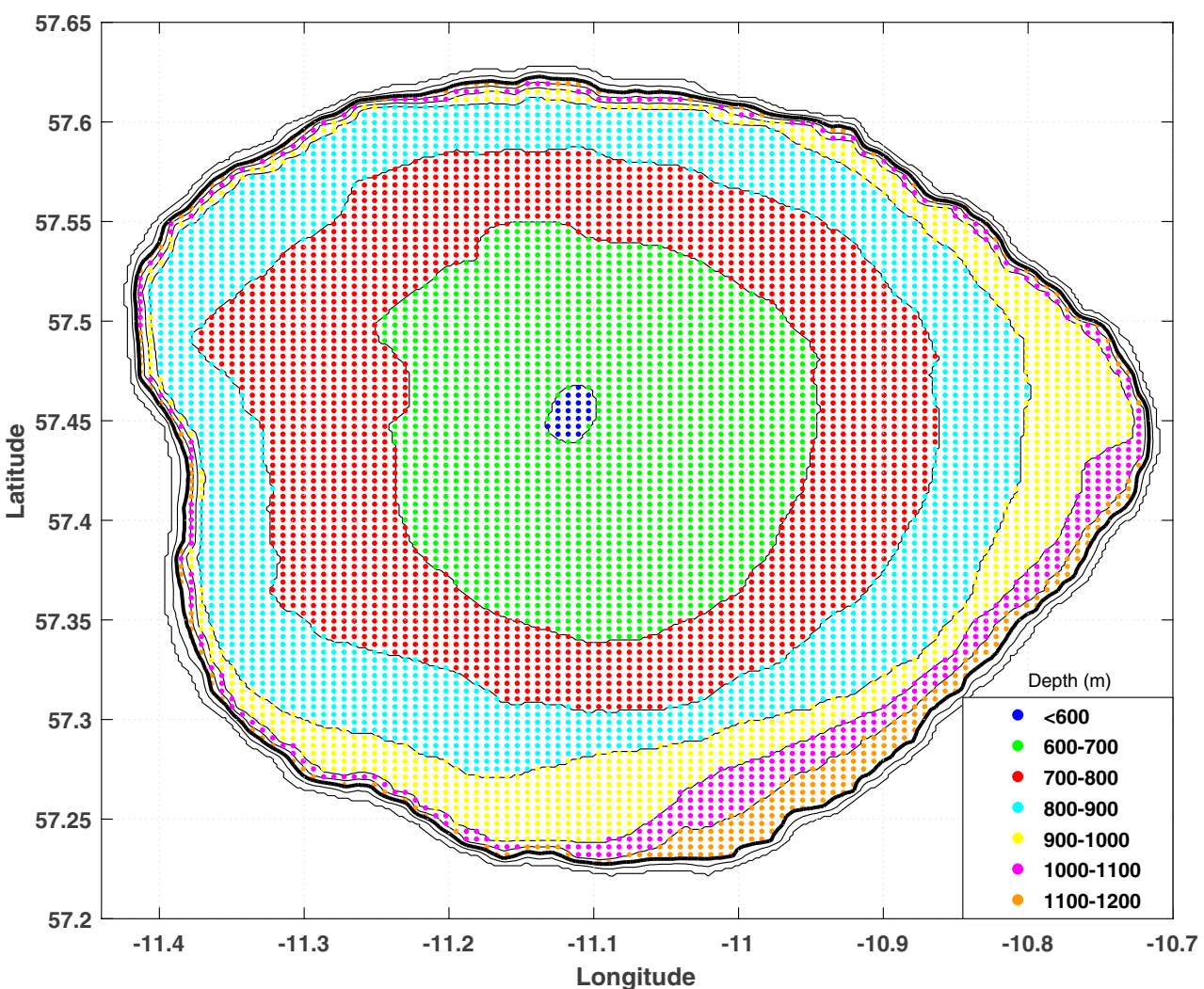




\section{Experiment on larvae dispersion}

The aim of the numerical experiments on larval dispersal over ADS was in understanding the behaviour of the cloud of larvae. Seven thousand five hundred particles were seeded uniformly on the seamount surface up to 1200 $\mathrm{m}$ depth with $350 \mathrm{~m}$ spatial step. The experiments were designed in such a way to reproduce the pathway of larva particles from all points at the bank surface, but most importantly, to find their positions after 40 days of floating. Figure 7 shows the initial locations of all particles coloured differently depending on the range of water depth.

Figure 8 presents the final position of all particles after 40 days of model time for four different scenarios. Specifically, in each case, the particles were released from the very same location but with a 3-h time interval (a quarter of the tidal period). Qualitative analysis of two-dimensional patterns presented in Fig. 8 shows that the vast majority of particles ultimately settled on the seamount. They were deposited either locally, or not far away from their depth range. However, some particles were able to escape from

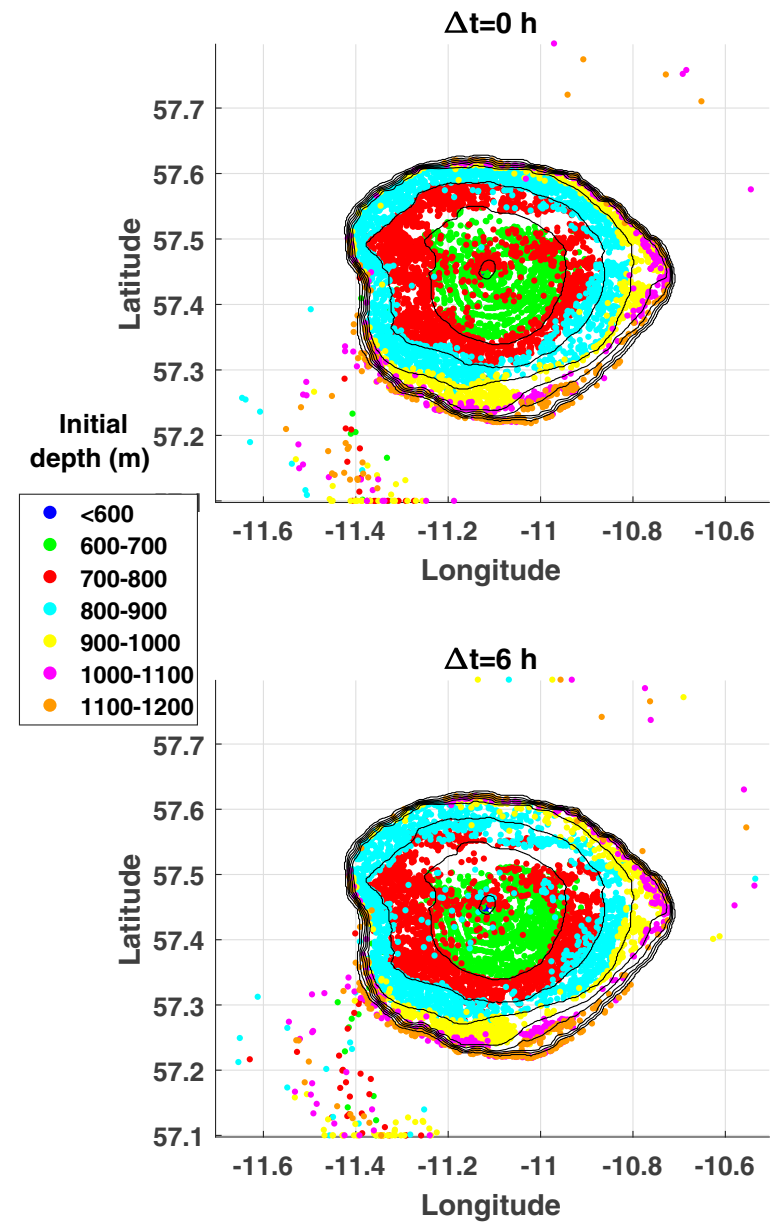

the seamount, although some of them sunk deeper than $1400 \mathrm{~m}$ deep, below which the particle trajectories were not considered.

Figure 9 quantitatively confirms the conclusion formulated above that, in general, the particles do not travel a lot. Here, four pie graphs (one for each tidal phase) show a proportion of particles that escaped from the topography (yellow), remained at the seamount (green) or sunk to the deep (blue). It reveals that only every tenth larva particle can leave the topography and has a chance to be advected to any other remotely located seamount. All others are potentially locally recruited. Another outcome of the experiment is that the tidal phase is not so important for the ultimate fate of larval dispersal. Every single trajectory of a larva particle can be different from others' and unique, but on average, an ensemble of passive particles is not sensitive to the tidal phase.

It should be noted here that in the described experiment, the initial position of the particles was $5 \mathrm{~m}$ above the bottom. To understand how sensitive the results of particle tracking from the released depth could be, an extra experiment with
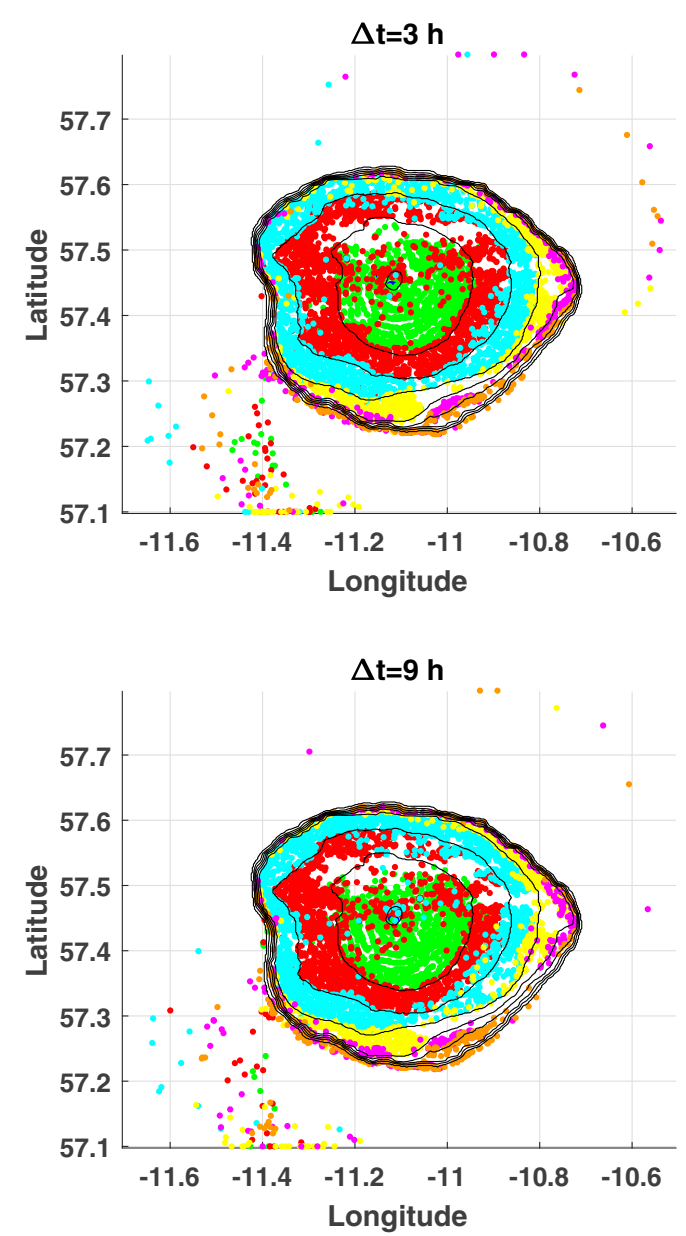

Fig. 8 Particles' positions after 40 days of the model run for different phases of the tidal cycle. The colours correspond to the initial design shown in Fig. 7 
$\Delta \mathrm{t}=\mathbf{0} \mathrm{h}$

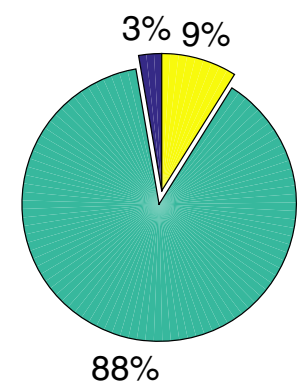

Deep

$\ln \square$ Out
$\Delta \mathrm{t}=6 \mathrm{~h}$

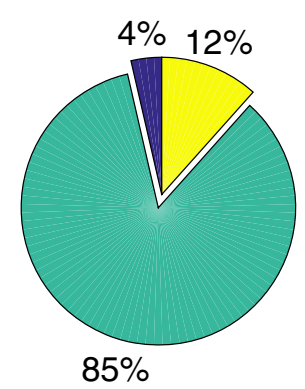

Deep
$\Delta t=3 h$

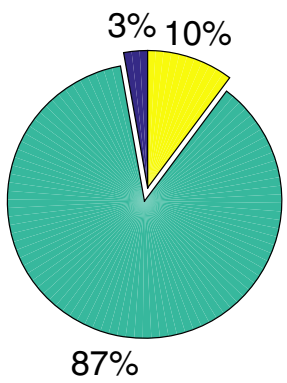

$\Delta t=9 h$

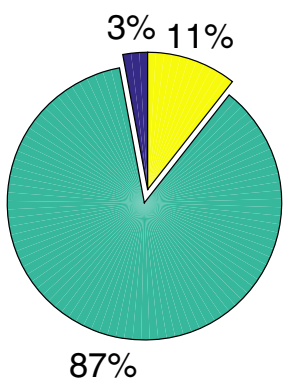

Deep $\square$ In $\square$ Out

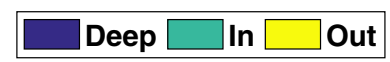

Fig. 9 Pie schemes showing the percentage of particles settled (green), escaped (yellow), and sunk deep (blue) for four tidal phases $\Delta t$

1-m initial particle height above the bottom was performed. It was found for the tidal phase $\Delta t=0$ that the total amount of the settled on the seamount particles was only $0.6 \%$ larger than that in the previous experiment.

The analysis presented above is helpful in understanding the larva behaviour, i.e. how far the particles can migrate from their initial positions and how many of them do not travel a lot. Note, however, that this consideration does not answer the question of how many particles have already settled, and how many of them are still in suspension. Figure 10 shows that after 40 days of the model experiment, some particles continue to move above the summit. Figures $5 \mathrm{~b}$ and $5 \mathrm{c}$, which show tidally induced vertical circulation cells, can give a clue why the larvae are still in motion. The upward fluxes are located just in the centre of ADS.

Analysis of the particle trajectories has shown that they were settled at different moments of time. The question whether the settled larvae can give rise to a new coral colony depends on the time of deposition. According to the investigation of Larsson et al. (2014), the nematocysts that are needed to make larvae settle appear when they are
30 days old. Thus, if the larva particle sinks to the bottom before 30 days after its release and becomes motionless, it would be unable to develop into a future coral. So, we consider the particles that settled before 30 days from the beginning of the experiment as dead larvae.

Four pie graphs presented in Fig. 11 that correspond to the 3-h time lag quantify the number of particles settled before the competency period (yellow) and the percentage of larvae remaining in suspension after 40 days (red). The difference between the two (green) is the number of particles $(<1 \%)$ that settled at ADS between 30 and 40 days of their lifetime, and thus, those passive larvae underwent maximum dispersal but have successfully recruited to the benthos. After 40 days, 6-9\% of particles are still in suspension above ADS.

The next objective of our study was the identification of the initial position of the particles which are still in suspension after 30 days of their life (the areas of the seamount that support the widest dispersal). Figure $12 \mathrm{a}$ shows the initial position of such particles overlaid in one graph for four considered tidal phases, and Fig. 12b presents their trajectories over 40 days of their lifetime. A comparison of Figs. $12 \mathrm{~b}$ and 7 shows that the vast majority of the particles do not leave their initial depth range. However, some of the particles initially located on the flank between the 700- and 800-m isobaths have moved to the centre of ADS ending up between the 600- and 700-m isobaths. The vast majority of the particles after 40 days of their evolution remain at the depth band where they were initially released. Another conclusion that Fig. 12 clearly shows is that there is no apparent connection between the southern and northern parts of the seamount.

Figure 13a shows the initial positions of the particles that were able to escape from ADS, and Fig. 13b depicts their 40-day trajectories. Similar to the previous graph, all particle trajectories released at four different tidal phases are overlaid in one plot. It is clear from Fig. 13b that particles were trapped by the tidally generated eddies shown in Fig. 5a. They were transported mostly in south-westerly or north-easterly directions. Different colours of the escaped particles (Fig. 7) suggest that they can be transported from all considered depths (with the exception of maybe the shallowest part in the seamount centre where the water depth is less than $600 \mathrm{~m}$ ). In the vertical direction, the escaped particles occupy the whole water column, from 400 to $1400 \mathrm{~m}$ depth (the model was restricted by this depth range).

\section{Summary and conclusions}

Connectivity of seamount populations remains an area of active study. However, the role of oceanographic processes 


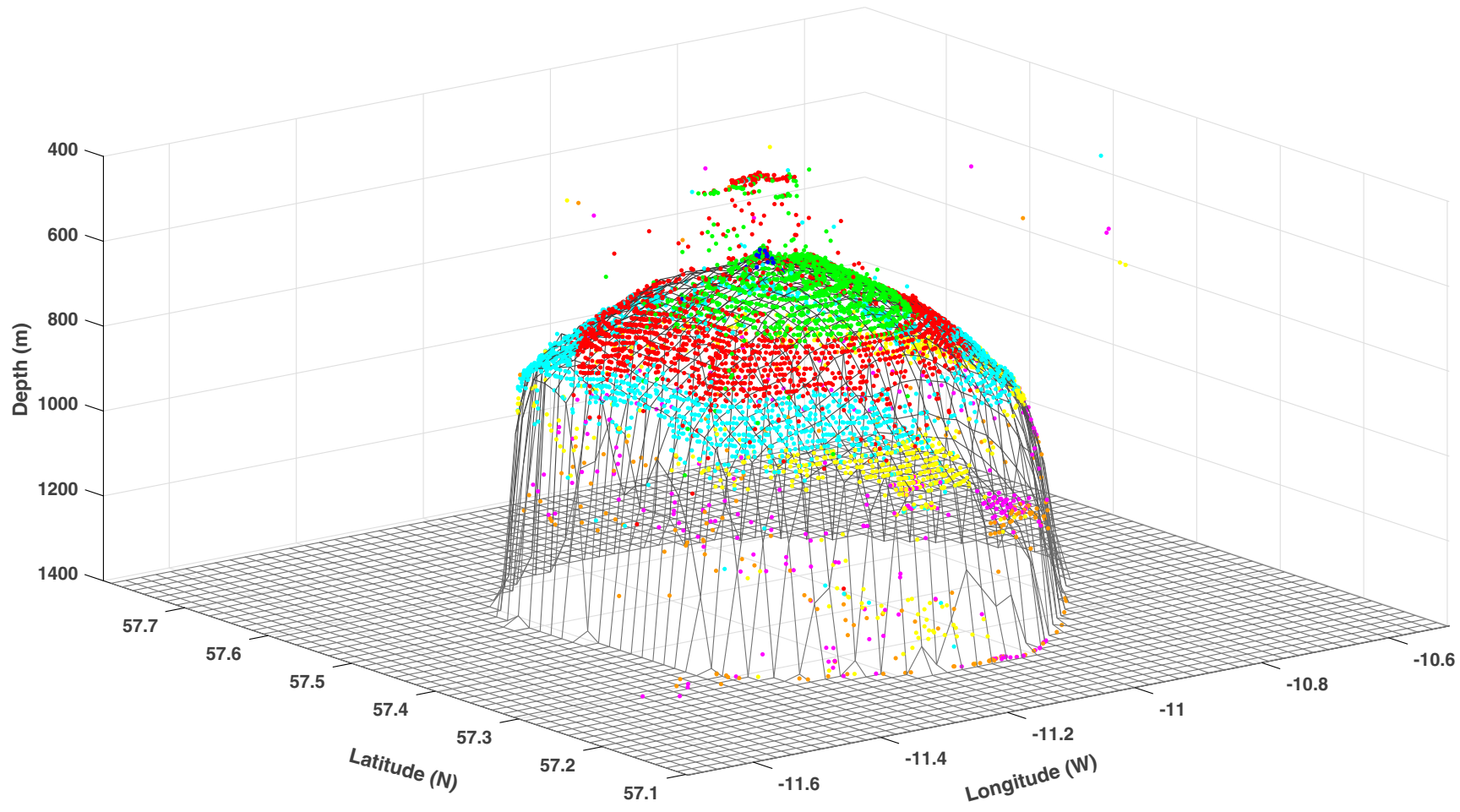

Fig. 10 Particles' positions in three dimensions after 40 days of the model run for $\Delta t=6 \mathrm{~h}$. The colours correspond to the initial design shown Fig. 7

as a potential isolating mechanism, and in determining observed patterns of poor connectivity over the depth gradient, remains unknown. According to Sherwin et al. (2015), the strongest currents in the surface $400 \mathrm{~m}$ layer in this area do not exceed $\sim 20 \mathrm{~cm} \mathrm{~s}^{-1}$. The currents are even weaker below this level. Under such conditions, the water circulation at those banks below $600 \mathrm{~m}$ depth is mostly controlled by tides.
Fig. 11 Pie schemes showing the percentage of particles settled before the first 30 days (yellow), remaining in suspension after 40 days (red), and settled down between 30th and 40th days of the numerical experiment (green). The $\Delta t$ time (hours) indicates the time after the beginning of the tidal cycle
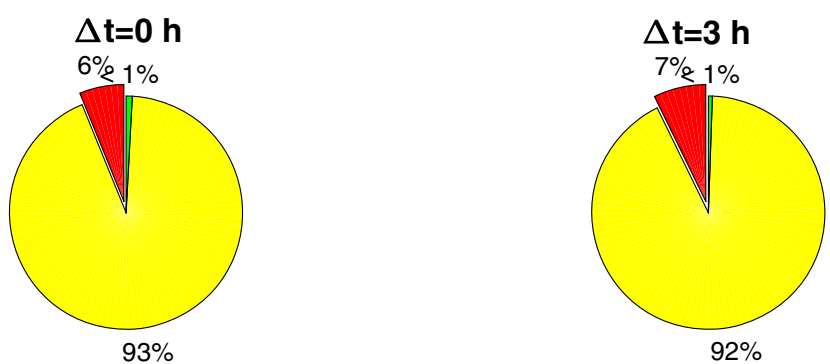

Alive $\square=$ days $\square$ in next $\Delta t=10$ days

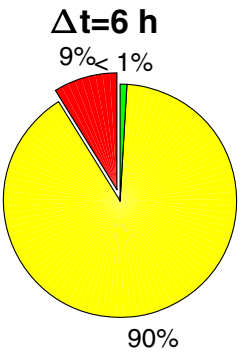

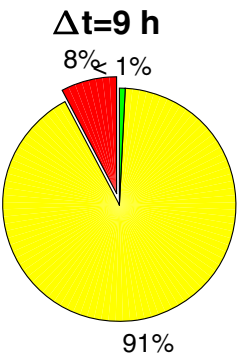



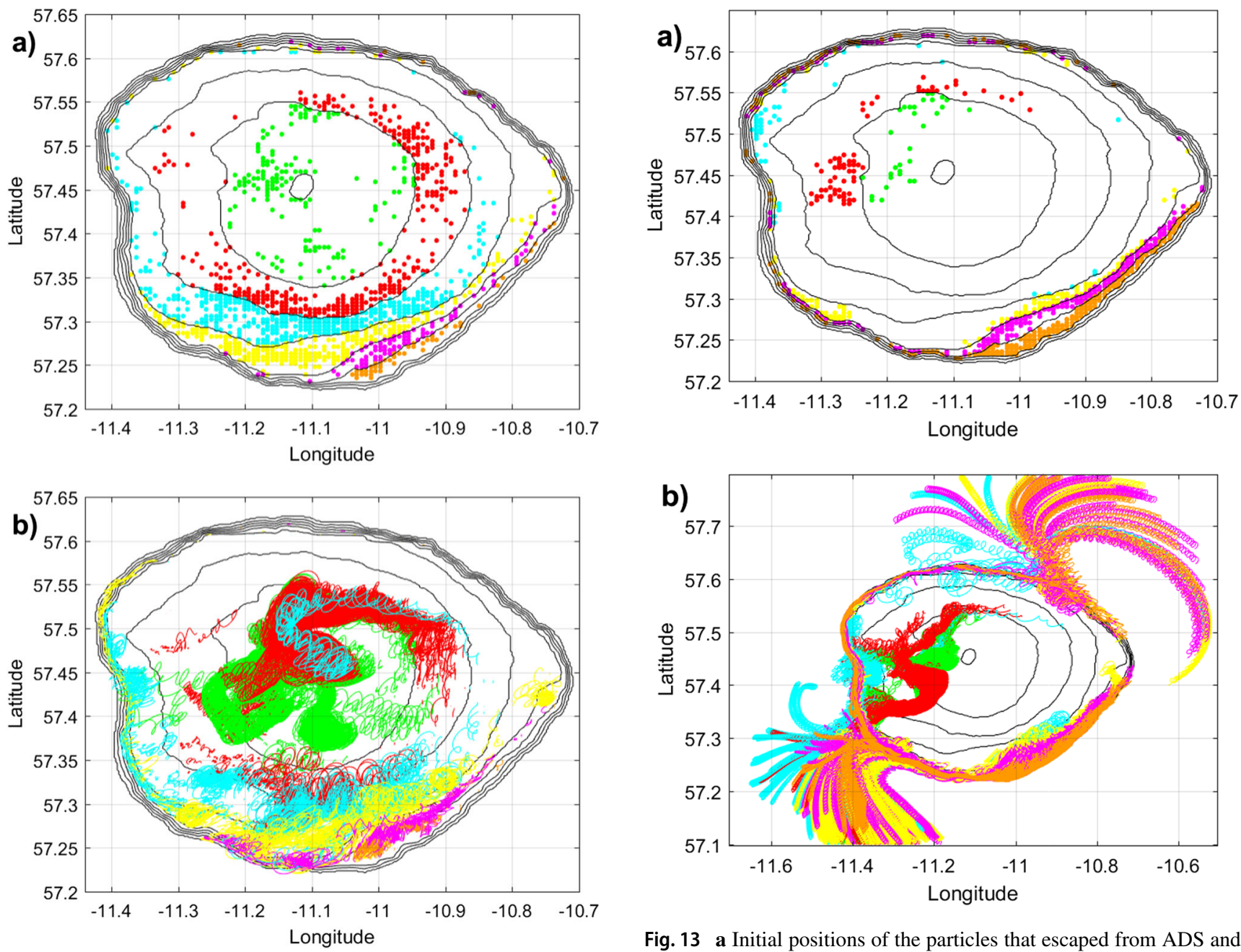

Fig. 13 a Initial positions of the particles that escaped from ADS and b their 40-day trajectories. All four model experiments with different

Fig. 12 a Initial positions of particles that are still flying after 30 days of the model time (all four tidal phases are shown together) and $\mathbf{b}$ their trajectories over 40 days

Vlasenko et al. (2018) conducted a detailed analysis of baroclinic tidal activity over Anton Dohrn Seamount. The MITgcm was used for investigation of the interaction of the semi-diurnal tidal flow with ADS. A consistency of the model output with the in situ collected data was a starting point for the present study of quantification of larva dispersion near ADS, i.e. use of the model-predicted fine-resolution velocity fields (115-m horizontal and $10-\mathrm{m}$ vertical resolutions) as an input data for a Lagrange-type passive tracer tracking model. A series of 5-min model outputs of the velocity components were used for a threelinear interpolation of larva evolution evenly seeded initially at the ADS surface (7500 sites) and simultaneously released from the bottom.

Conducted numerical experiments have shown that the larvae that escape from ADS were captured by tidally generated residual currents that exist at the periphery of

ADS in the form of four eddies (two cyclonic and two anticyclonic vortexes). However, statistical wise, the probability of such an escape is not very high. It accounts for only 9-12\% of all released particles. Thus, only every tenth larva particle leaves the topography and has a chance to be transported to any other remotely located seamount. The vast majority of the particles started their motion above the 1000-m isobath remains seated in the same depth band where they were initially released.

The conclusions formulated above are purely based on the hydrodynamical processes developing around ADS. It was found here that only $6-9 \%$ of particles can undergo maximum dispersal with successful recruitment to the benthos.

Note that different sites of ADS do not contribute equally to a potential distant larva travel. Vlasenko et al. (2018) found that the main places of internal wave activity are the steep flanks of the ADS topography. As a result, the larva particles released here (below $1000 \mathrm{~m}$ depth) are the most 
mobile. They have a higher probability to escape from ADS or relocate to its deeper or shallower parts.

In general, the principal question on cold-water coral reef survival and sustainability is a good food supply to feed them. According to Frederiksen et al. (1992), the highest abundance of Lophelia pertusa corals around the Faroe Islands tends to be at depths where the bottom slope is critical to internal waves of semi-diurnal frequency. The casual link behind this is suggested to be an increase of food availability either through higher primary production at the surface or by a redistribution of suspended particles in the bottom mixed layer.

Acknowledgements The authors would like to thank the Captan, Crew and Scientific Parties, especially the ROV ISIS team working during the JC136 cruise. We thank two anonymous reviewers and Associate Editor Prof. Jarle Berntsen for their useful comments.

Funding information This work was supported by the UK NERC grant NE/K011855/1

Open Access This article is distributed under the terms of the Creative Commons Attribution 4.0 International License (http://creative commons.org/licenses/by/4.0/), which permits unrestricted use, distribution, and reproduction in any medium, provided you give appropriate credit to the original author(s) and the source, provide a link to the Creative Commons license, and indicate if changes were made.

\section{References}

Bartsch J, Coombs S (1997) A numerical model of the dispersion of blue whiting larvae, Micromesistius poutassou (Risso), in the eastern Atlantic. Fish Oceanogr 6(3):141-154

Buhl-Mortensen L, Olafsdottir SH, Buhl-Mortensen P, Burgos JM, Ragnarsson SA (2015) Distribution of nine cold-water coral species (Scleractinia and Gorgonacea) in the cold temperature North Atlantic: effect of bathymetry and hydrography. Hydrobiologia 759(1):39-61

Buhl-Mortensen P, Gordon DC Jr, Buhl-Mortensen L, Kulka DW (2017) First description of Lophelia pertusa reef complex in Atlantic Canada. Deep-Sea Res I 126:21-30

Davies JS, Stewart HA, Narayanaswamy BE, Jacobs C, Spicer J, Golding N, Howell KL (2015) Benthic assemblages of the Anton Dohrn Seamount (NE Atlantic): defining deep-sea biotopes to support habitat mapping and management efforts with a focus on vulnerable marine ecosystems. PloS one 10(5):pe0124815

Frederiksen R, Jensen A, Westerberg H (1992) The distribution of the scleractinian coral Lophelia pertusa around the Faroe Islands and the relation to internal tidal mixing. Sarsia 77:157-171

Henry L-A, Vad J, Findlay HS, Murillo J, Milligan R, Roberts JM (2014) Environmental variability and biodiversity of megabentos on the Hebrides Terrace Seamount (North Atlantic). Sci Rep 4(5589): $1-10$

Hilário A, Metaxas A, Gaudron SM, Howell KL, Mercier A, Mestre NC, Ross RE, Thurnherr AM, Young C (2015) Estimation dispersal distance in the deep sea: challenges and applications to marine reserves. Front Mar Sci 2:6. https://doi.org/10.3389/fmars. 2015.00006

Egbert GD, Erofeeva SY (2002) Efficient inverse modeling of barotropic ocean tides. J Atmos Oceanic Technol 19(2):183-204

Georgian SE, Shedd W, Cordes EE (2014) High-resolution ecological niche modelling of the cold-water coral Lophelia pertusa in the Gulf of Mexico. Mar Ecol Prog Se 506:145-161

Larsson AI, Järnegren J, Strömberg SM, Dahl MP, Lundälv T, Brooke S (2014) Embryogenesis and larval biology of the cold-water coral Lophelia pertusa. Plos One 9(7):1-14

Marshall J, Adcroft A, Hill C, Perelman L, Heisey C (1997) A finite-volume, incompressible Navier-Stokes model for studies of the ocean on the parallel computers. J Geophys Res 102:57335752

McClain CR (2007) Seamounts: identity crisis or split personality? J Biogeogr 34(12):2001-2008

Pacanowski RC, Philander SGH (1981) Parameterisation of vertical mixing in numerical models of Tropical Oceans. J Phys Oceanogr 11:1443-1451

Pingree RD, Maddock L (1980) Tidally induced residual flows around an island due to both frictional and rotational effects. Geophys J R astr Soc 63:533-546

Sherwin T, Aleynik D, Dumont E, Inall ME (2015) Deep drivers of mesoscale circulation in the central Rockall Trough. Ocean Sci 11:343-359

Stashchuk N, Vlasenko V, Inall ME, Aleynik D (2014) Horizontal dispersion in shelf seas: high resolution modelling as an aid to sparse sampling. Progr in Oceanogr 128:74-87

Stashchuk N, Vlasenko V, Hosegood P, Nimmo-Smith A (2017) Tidally induced residual current over the Malin Sea continental slope. Cont Shelf Res 139:21-34

Thiem Ø, Ravagnan E, Fosså JH, Berntsen J (2006) Food supply mechanisms for cold-water corals along a continental shelf edge. J Mar Systems 60:207-219

Vlasenko V, Stashchuk N, Nimmo-Smith WA (2018) Threedimensional dynamics of baroclinic tides over a seamount. J Geophys Res 2:1263-1285. https://doi.org/10.1002/2017JC013287 